\title{
A MATRIZ PEDAGÓGICA JESUÍTA E A SISTEMÁTICA ESCOLAR MODERNA
}

DOI: http://dx.doi.org/10.1590/2236-3459/71138

\author{
Teresa Maria Rodrigues da Fonseca Rosa \\ Instituto de Educação, Universidade de Lisboa, Portugal
}

$\cos 8$

\begin{abstract}
Resumo
A Ratio foi, como o próprio nome indica, a ordenação ou sistematização dos estudos, a primeira que se fez no mundo. Se algumas das características da metodologia que os primeiros Jesuítas aplicavam à educação podem parecer demasiado simples, ou mesmo elementares, têm nos nossos dias a sua atualidade. A emulação foi um dos motores da pedagogia dos Jesuítas: Honesta aemulatio chama-lhe a Ratio, Sancta aemulatio haviam-Ihe chamado as Constituições. O facto de a emulação ser uma componente fundamental da pedagogia Jesuíta, levou a que os seus alunos estivessem constantemente ativos e, desse modo, participassem, empenhadamente, no processo ensino-aprendizagem. Este estudo permitiu-nos concluir, que estamos perante um modelo de grande contemporaneidade.

Palavras-chave: instituições inacianas, Ratio Studiorum, ensino, motivação.
\end{abstract}

\section{THE JESUITS PEDAGOGIC MATRIX AND THE MODERN EDUCATION SYSTEM}

\begin{abstract}
The Ratio consisted in the systematization and ordering of studies which was unique worldwide. Even if some of the characteristics of the educational methodology, followed by the first Jesuits, appeared to be rather simple, or even elementary, it is still applicable nowadays. The emulation has been one of the main drivers of Jesuit's pedagogy: Honesta aemulatio called by Ratio or Sancta aemulatio called by Constitutions. The emulation, as one of the key components of Jesuit pedagogy, led its learners to have an active role and consequently to participate with enthusiasm in the teaching-learning process. The development of this study contributed to conclude that this model is still maintain great contemporaneity.
\end{abstract}

Keywords: inatian Institutions, Ratio Studiorum, education, motivation.

\section{EL MODELO PEDAGÓGICO JESUITA Y EL SISTEMA EDUCATIVO MODERNO}

\section{Resumen}

La Ratio fue, como su propio nombre indica, la ordenación o sistematización de los estudios, la primera que tuvo lugar en todo el mundo. Si algunas de las características de la metodología que los primeros jesuitas aplicaron a la educación pueden parecer demasiado simples, o incluso elementales, este hecho recobra todo el sentido en la actualidad. El estímulo fue siempre uno de los motores de la pedagogía de los jesuitas: Honesta aemulatio lo denomina la Ratio, Sancta aemulatio lo habían llamado las Constituciones. El hecho de que la emulación fuera un componente fundamental de la pedagogía jesuita implicaba permanentemente a los alumnos en el proyecto y que, de ese modo, participasen de forma activa en el proceso de enseñanza- 
aprendizaje. Este estudio nos ha permitido concluir que estamos ante un modelo de gran contemporáneo. Palabras clave: instituciones ignacianas, Ratio Studiorum, enseñanza, motivación.

\section{LA MATRICE PEDAGOGIQUE JESUITE ET LA SYSTEMATIQUE SCOLAIRE MODERNE}

\section{Résumé}

Le Ratio fut, comme son nom l'indique, l'ordination ou la systématisation des études, la première jamais effectuée. Si certaines des caractéristiques de la méthodologie appliquée à l'éducation par les premiers Jésuites peuvent paraître simples, voire simplistes, elles ont encore toute leur place de nos jours. L'émulation a été l'un des moteurs de la pédagogie des Jésuites: le Ratio l'appelle Honesta aemulatio tandis que les Constitutions l'avaient baptisée Sancta aemulatio. Le fait que l'émulation soit une composante fondamentale de la pédagogie jésuite a conduit ses élèves à être constamment acteurs et, ainsi, à participer vigoureusement au processus enseignement-apprentissage. Cette étude nous a permis de conclure au caractère grand contemporain de ce modèle.

Mots-clés: institutions ignatiennes, Ratio Studiorum, enseignement, motivation. 


\section{Introdução}

Companhia de Jesus fundada sob a égide de Santo Inácio de Loyola e
aprovada por Paulo III, a 27 de setembro de 1540, através da Bula Regimini
Militantis Ecclesiae, cuja formulação foi reelaborada a 21 de julho de 1550 pela Bula Exposcit Debitum de Júlio III, tinha como objetivos principais: a pregação, a prática da caridade e educação da juventude.

O ideal pedagógico dos primeiros Jesuítas reflete o estilo próprio de Inácio de Loyola. A sua pedagogia nasce, sobretudo, de uma época marcada por acontecimentos profundamente relevantes que a influenciaram. Contudo, na base de todos os princípios inspiradores esteve a fé cristã e a sua visão do mundo e da vida.

A sua originalidade não se encontra apenas numa certa forma de sensibilidade religiosa, mas sim na transformação da sua experiência pessoal numa experiência de ação pedagógica, caracterizada por uma "dimensão mística". Dirigida para o serviço dos homens numa missão de apostolado, patente não só no livro dos Exercícios Espirituais, mas também nas Constituições da Companhia de Jesus e nas diversas "ordenações de estudos", anteriores ao texto original e definitivo do Ratio Studiorum, de 1599.

Essa pedagogia, não nascendo de um dia para o outro, foi mérito dos primeiros Jesuítas dos séculos (XVI a XVIII), que aproveitaram toda a riqueza cultural do Humanismo, adotando um conjunto de técnicas pedagógicas, que no tempo do seu fundador eram, sem dúvida, das mais avançadas e encontram-se representadas no Modus Parisiensis, isto é, na metodologia educativa desenvolvida na Universidade de Paris.

Inácio de Loyola nunca escondera a sua admiração por este modelo, pois oferecia ordem, rapidez na aprendizagem, exercício, disciplina e sobretudo eficácia no método, considerando-o, assim, o mais eficaz para atingir os objetivos pretendidos para os seus Colégios, conforme atestam as palavras de Bertrand-Quera (1986, p. 27):

Hablando de métodos, Ignacio de Loyola repetidamente habia expressado de palabra e por cartas su admiración por la eficacia del método didáctico que se seguia en la Universidad de Paris y que el habia experimentado en carne própria particularmente en el Colégio de Santa Barbara. Por esta razón quiso implantado decididamente en la pedagogia de los Jesuítas. El mérito de Ignacio de Loyola no es en este punto, el de ser su autor original, sino el de haber sabido descobrir su valor formativo y haberlo adaptado después a todos los niveles de la ensenanza de los Jesuítas.

Podemos salientar também, que o Colégio de Messina, fundado em 1548, o primeiro Colégio Jesuíta criado para a educação da juventude, e dirigido por Jerónimo de Nadal, assentou nesta base pedagógica Modus Parisiensis e serviu de modelo para fundações congéneres. Jerónimo Nadal, logo no início das aulas, fez publicar um prospeto Scopus et Ordo Scholarum Messanensium que continha o primeiro plano de estudos de um Colégio Jesuíta, onde o método seguido era bem explicitado, como verificamos: a gramática e a língua latina eram ensinadas em três classes distintas, cada uma das quais com o seu professor, "o qual se ocupava apenas dos seus próprios alunos". A divisão de classes seguida em Paris, e raramente em Itália ${ }^{1}$ estabelecia a distribuição das matérias em níveis sucessivos. Em cada uma das três classes, além das lições, far-se-iam correntemente

${ }^{1}$ Conforme o Modus Italicus. 
repetições, competições entre alunos, composições, declamações e outros exercícios semelhantes.

Pouco depois, Jerónimo Nadal publicou as Constituições do Colégio de Messina, que eram um regulamento escolar dividido em duas partes: a primeira constituía o primeiro regulamento disciplinar para os estudantes externos; a segunda desenvolvia os programas dos cursos e o método a seguir, já esboçado anteriormente no "prospeto". Estas Constituições estão na base de todos os documentos escolares mais importantes, elaborados em Roma para os Colégios das diferentes Províncias da Companhia.

Deste documento, serviu-se também Juan Polanco, em 1551, para redigir o Regulae Rectoris Collegi Romani, e algumas passagens foram integradas na parte IV das Constituições da Companhia, no capítulo $7^{\circ}$ respeitante aos Colégios.

Segundo Codina Mir (1968), as principais características do Modus Parisiensis repartiam-se nos quatro tópicos seguintes: a distribuição dos alunos em classes; a atividade constante dos alunos nos seus exercícios escolares; os incentivos para o trabalho escolar; e a união da piedade e dos bons costumes com as letras.

Foi este o ponto de partida, para todo o desenvolvimento posterior, com base em experiências pedagógicas diversas que iriam ser codificadas no Ratio Studiorum de 1599, servindo de tronco educativo a todos os Colégios inacianos. Continham toda uma série de "regras" autênticas, diretrizes de caráter prático, que se referiam a várias questões diferentes, tais como: os aspetos da formação e distribuição de professores, os programas e métodos de ensino. Nelas se dão igualmente indicações sobre o comportamento dos alunos.

O sistema pedagógico permitia, ainda, uma sólida formação em letras humanas, seguida de estudos de filosofia, que culminava nos estudos teológicos.

Tomada a decisão de incluir a instrução como um dos meios mais eficazes para atingir os objetivos a que a Companhia se propunha, tornou-se necessário elaborar um documento que orientasse essa atividade, e que ficasse consagrada na lei fundamental: as suas "Constituições". Na parte IV, escrita em dois momentos distintos, por Inácio de Loyola, desde 1549 até à data da sua morte em 1556, encontramos o mais importante do seu pensamento sobre educação. Composta por dezassete capítulos e um prólogo intitulado "Como instruir nas letras e em outros meios de ajudar o próximo os que permanecem na Companhia" (ABRANCHES, 1975, p. 10). Os restantes capítulos são dedicados às Universidades da Companhia.

Na parte IV, encontramos os principais aspetos pedagógicos que estão na origem da regulamentação posterior, sendo toda dedicada à educação e à formação dos Jesuítas formados e em formação, e referente à orientação de caráter metodológico, revelando o interesse que Inácio de Loyola tinha pelo apostolado da educação.

Afirma Rodrigues (1917, p. 15-16) que:

A quarta parte das Constituições a mais pormenorizada e extensa das dez grandes divisões do livro, é, de facto, um compêndio, um verdadeiro programa escolar (...). Dali se desenvolveu como germe pequenino o Ratio Studiorum, em esse plano de estudos alvo de juízos tão encontrados que dirigiu como método universal a educação e o ensino subministrado pelos Jesuítas em todas as partes do mundo.

Podemos considerar ainda esta parte como o primeiro esboço da Ratio Studiorum, 
como sugere Lopes (2002, p. 99), "a intenção inaciana, ao escrever estes breves dezassete capítulos [...] era a de dar uma semente para futuros documentos, especialmente a Ratio Studiorum".

O legislador ali vai escrevendo: o modo de aceitar as fundações dos Colégios; o modo de se comportarem os escolásticos; os estudos que devem seguir; a organização das diversas classes e Faculdades; assim como, a educação espiritual, que se deve dar aos alunos.

Contudo, importa realçar também que se algumas das características da metodologia, que os primeiros Jesuítas aplicavam à educação, parecem demasiado simples, ou mesmo elementares, por outro lado, podemos considerar que algumas delas têm nos nossos dias a sua atualidade, a destacar:

- Os alunos não deviam estar na aula de um modo passivo, mas, pelo contrário, eram desafiados a ser participativos;

- Os professores tinham obrigação de prestar atenção individualizada na sala de aula;

- O ensino tinha em conta a idade dos alunos e a sua personalidade.

Constatamos, assim, que estamos perante algumas características educativas, que não eram de modo algum comuns na época de Loyola, pelo que os Colégios inacianos têm mérito na sua divulgação, fazendo-as chegar aos nossos dias, bem como outros princípios fundamentais de cariz espiritual inaciana, que fizeram e fazem parte do Modelo Educativo da Companhia de Jesus através dos tempos.

\section{A Ratio Studiorum e o ministério escolar}

No séc. XVI, foram elaborados cinco Ratio que merecem ser destacados: os de Nadal, os de Coudret, os de Ledesma e Borja, e o definitivo de Aquaviva (quarto Prepósito Geral da Companhia, que unificou e promulgou oficialmente o Ratio atque Institutio Studiorum de 1599). Este texto foi publicado em Nápoles, em 8 de janeiro de 1599. (ROSA, 2015, p. 75).

Com o crescente aumento do número de Colégios, tornava-se urgente que a Companhia de Jesus tivesse, na medida do possível, uma ordem de estudos comuns. Na procura de um regulamento universal, salientam-se diversos companheiros de Inácio de Loyola, como o seu secretário, o Padre Polanco. Este, estudando os programas das Universidades de Valência, Salamanca, Alcalá, Coimbra, Paris, Lovaina, Colónia, Bolonha e Pádua, foi o redator das orientações dos estudos, utilizados nos primeiros Colégios.

A outro Jesuíta, Jerónimo de Nadal, que exerceu forte influência na ordem das Constituições dos estudos, cabe o mérito de redigir um primeiro Ratio, em 1548, como salientámos anteriormente. A este Ratio deu-se o nome de Studiis Societatis Jesu et Ordo Studiorum e é considerado como o núcleo do futuro Ratio de Aquaviva de 1599 (ROSA, 2005, p. 372). Nadal unificou também todas as iniciativas dispersas dos Colégios de Espanha, Portugal, Itália, França e Alemanha e, para tal, muito contribuíram as suas visitas como comissário da Companhia.

A primeira originalidade do programa de estudos da Ratio consistia, por um lado, 
em se destinar simultaneamente à formação de religiosos e de leigos, por outro, no facto de incluir, além de filosofia e da teologia, o estudo sistemático das humanidades: as línguas a literatura, a retórica, a história, e o teatro escolar, sendo este, certamente, o "maior distintivo da proposta pedagógica da Companhia de Jesus", como afirma Miranda. (2009, p. 27).

A Ratio foi, como o próprio nome indica, a ordenação ou sistematização dos estudos, a primeira que se fez no mundo. O documento não pretendeu ser um tratado pedagógico, porque os Jesuítas já tinham assimilado, na própria formação religiosa, os princípios pedagógicos provenientes da experiência, da visão e dos escritos do fundador da Companhia de Jesus, nomeadamente, os Exercícios Espirituais. Por isso, a Ratio tal como Gomes (1994, p. 143-144) sublinha:

não é um tratado de pedagogia, mas um código, um programa, uma lei orgânica que se ocupa do conteúdo do ensino ministrado nos Colégios e Universidades da Companhia de Jesus e que se impõe métodos e regras a serem observados pelos responsáveis e pelos professores desses Colégios e Universidades.

Assim, falar da Ratio Studiorum é falar de um texto fundador que permitiu o desenvolvimento de um sistema escolar de alcance internacional.

A rede de Colégios, que os Jesuítas criaram em toda a Europa, constituiu efetivamente um sistema escolar dotado de um plano de estudos e regulamento próprios, cuja experiência se deve a uma reflexão prévia, que acompanhou anos de experiência, em todas as províncias. Depois de muitas reformulações feitas, ao longo de meio século, virá a ser finalmente aprovada em 1599, com o título de Ratio atque Institutio Studiorum. No entanto, Inácio de Loyola nunca elaborou nenhuma Ratio.

Qualquer que fosse o curso a seguir, o programa de estudos da Ratio combinava os estudos das humanidades com os estudos científicos. Assim se devia formar homens que soubessem pensar e escrever; com elevados conhecimentos de literatura, de história, de geografia e de artes; com um profundo entendimento de matemática, de astronomia e as restantes ciências naturais; com desenvolvido sentido crítico, apurado pela retórica e pela filosofia. Homens preparados para intervir em nome do bem comum, isto é, formados numa educação que reconhece a utilidade social da retórica.

Uma sólida instrução literária era vista como um contributo indispensável para a educação do homem de bem. A todos os professores, a Ratio tornava presente que a principal finalidade dos estudos era o maior "serviço" e que todos os estudos deviam concorrer para esse fim, unir a "virtude às letras".

O Modus Parisiensis, explicitamente evocado como inspirador, refletia-se em dois aspetos fundamentais: a atividade individual e permanente do aluno, por um lado, e uma clara distinção entre graus de ensino, graus de aprendizagem, assim como, ordem das matérias, do menos complexo para o mais complexo, por outro.

Associados a este método, encontravam-se também os incentivos, que se poderiam caracterizar por castigos, prémios ou louvores, ou mesmo a emulação, conhecidos como meios para encorajar o trabalho e motivar os estudantes. A emulação entrava em jogo quando dois "exércitos" de alunos se confrontavam entre si. O vencedor tinha direito a prémios (MONTEIRO, 1991). Fazia ainda parte, a distribuição dos alunos por ordem de mérito, dentro de cada classe. 
Desta forma, Inácio de Loyola concretiza o Modus Parisiensis com cinco ideiaschave, como atesta Lopes (2002):

- Deve haver uma distribuição das classes, de acordo com a capacidade dos estudantes;

- Deve cada classe ter um professor;

- Deve haver uma progressão nos estudos, das classes inferiores até às mais altas: gramática, retórica, humanidades, artes, (filosofia e matemáticas) e teologia, mas somente uma de cada vez;

- Os alunos devem ser assíduos na assistência às aulas. Não deve haver dispersão nas leituras;

- As lições devem ser acompanhadas de abundância de exercícios. Por isso haverá repetições, disputas e composições que são fundamentais.

A preocupação pelo método leva os autores da Ratio a prestarem, pela primeira vez, uma cuidadosa atenção à preparação dos professores, cientes de que, para favorecer o estudo das letras, era necessário favorecer os seus mestres, começando pelas próprias qualificações, e assegurando o seu compromisso pessoal na missão específica do ensino. (MIRANDA, 2009).

$\mathrm{Na}$ história da educação, esta é talvez a primeira vez que se reconhece teoricamente a necessidade de preparar os professores para a sua atividade. Gomes (1994, p. 148) afirma mesmo que "a Companhia de Jesus foi a primeira instituição docente que se preocupou e se ocupou com a formação pedagógica dos professores". Alguns Jesuítas como Sacchini, Jouvancy, Wagner e Kropf, compuseram manuais de didática, destinados, sobretudo, aos futuros professores da Companhia.

As Constituições preocupavam-se com o perfil dos professores e indicavam já algumas das qualidades a eles dirigidas: "quer pertençam à Companhia quer não [...] é para desejar que estes sejam sábios diligentes e dedicados ao progresso dos estudantes, tanto nas aulas como nos exercícios escolares" (ABRANCHES, 1975, p. 140-141). Outros artigos acrescentam ainda: "[...] convém ao fim proposto que seja cuidadosamente tratado com excelentes professores". (ABRANCHES, 1975, p. 158).

Estes professores deviam interessar-se sempre pelo progresso de cada um dos alunos e pedir-Ihes conta das lições, fazendo-as repetir. Levarão também aos que estudam humanidades a exercitarem-se, a falar habilmente latim, a fazerem composições literárias e a declamá-las corretamente.

Para que se atingisse este nível ambicioso de preparação e formação dos futuros professores Jesuítas, era necessário um intenso treino e apoio contínuo na sua formação, uma vez que procuravam fazer deles verdadeiros Mestres dedicados à instrução.

Era, pois, evidente que fossem dadas ordens ao Provincial para que, na sua Província, se fundassem seminários de formação de professores. (ROSA, 2013).

Em síntese, a figura do professor, deveria ser a de um homem sabedor, ter método e possuir as qualidades morais e pedagógicas necessárias ao elevado ministério a desempenhar. 
Competia-Ihe ser um educador generoso, integrado com os alunos, num verdadeiro espírito familiar.

\section{Linhas gerais do currículo escolar e método na Ratio}

$\mathrm{Na}$ Ratio vêm delineadas, em forma de breves "regras", as funções dos responsáveis do Colégio a diversos níveis (Provincial, Reitor, Prefeito dos Estudos e Professores); a articulação do currículo formativo; as propostas no respeitante a horários; os programas de diversas lições: os métodos educativos e didáticos.

Inicialmente, não se admitia o grau elementar ou de primeiras letras, devido à falta de professores; esta condição, contudo, veio a sofrer alterações, em virtude da necessidade de escolas, sobretudo nas pequenas povoações. (MONTEIRO, 1991).

A estrutura curricular, estipulada na Ratio Studiorum, referia-se a três cursos. O curso de Letras, ao qual corresponde o primeiro ciclo, constituía os estudos inferiores e organizava-se do seguinte modo: três anos de gramática (classes ínfima, média e suprema), um ano de humanidades e mais um de retórica.

A finalidade pretendida no curso de Letras, "era a aquisição de uma expressão oral e escrita elegante e correta, erudita, de eloquência persuasiva, tudo porém em língua latina" (CARVALHO, 2011, p. 334). Só poderia ser promovido à classe seguinte o aluno que tivesse atingido o grau de conhecimentos exigidos. Cada classe, que era anual, tinha um professor próprio, com aulas diárias, que inicialmente eram de três horas, passando depois a duas horas e meia. Os alunos exercitavam-se diariamente na escrita e na composição, na aula e fora dela, insistindo-se na redação de textos, que deveriam ser recitados de cor. A seguir, ensinava-se humanidades com preleções diárias de Cícero e estudos de textos de vários autores. Do texto gramatical passava-se à exploração da poesia e da prosa de grandes autores Latinos, onde se incluía o estudo da História. A aula de humanidades preparava os alunos, através de preceitos da retórica, para a eloquência e para o domínio do vocabulário. A aula de retórica tinha como objetivo a formação de perfeitos oradores, assim como, a preparação na arte da poesia.

O método de ensino seguido no curso de Letras, exigia uma grande preparação dos professores e também um grande esforço de memória por parte dos alunos, que tinham de decorar os conteúdos estudados em cada aula para os utilizarem na hora seguinte.

Ao Curso de Letras, seguia-se o curso de Filosofia ou Artes. As matérias abrangidas eram a dialética, a lógica, a física e a metafisica, sendo Aristóteles o principal autor estudado. A duração era de três anos, com seis horas de aulas diárias. Este curso visava a "formação científica, por um lado, e encaminhava-se para um fim moral e religioso, por outro, tal como pretendia Inácio de Loyola". (MONTEIRO, 1991, p. 123).

E, por último, o curso de Teologia que constituía o mais elevado grau de preparação alcançado nos Colégios da Companhia: "as ciências são um meio e a teologia é o principal, escrevia Loyola nas suas Constituições" (ROSA, 2013, p. 39). Tinha a duração de quatro anos: o hebraico era estudado durante um ano, a Sagrada escritura durante dois anos e a Teologia moral durante dois anos.

Por detrás das exigências de formação humanística e educação cristã, estará sempre a proposta inaciana de associar, numa única unidade, "a virtude às letras".

Aspeto fundamental do método de ensino dos Jesuítas era a preleção. Segundo 
França (1952, p. 56), "a preleção é o centro de gravidade do sistema didático da Ratio". Consistia numa variedade de métodos utilizados pelo professor para as suas explicações, a sua finalidade era mais formativa do que informativa, visava desenvolver mais o espírito. Pressupunha uma excelente preparação destes.

Segundo as orientações da Ratio, o Mestre, que ensinava, devia assumir antes de mais, o papel de guia, orientador e estimulador dos alunos. Enquanto lente, cabia-Ihe o protagonismo no ato da preleção que, juntamente com a repetição e aplicação, por parte dos alunos, constituíam os três momentos principais da atuação escolar.

O aluno constituía o segundo momento, elemento do binómio do conjunto escolar, cabendo-Ihe o papel principal na fase de repetição das lições do Mestre, e na sua aplicação prática através dos exercícios de composição, debates e disputas públicas.

Desta forma, numa primeira fase, competia ao professor preparar e facilitar a aprendizagem do aluno, por meio da lição ou explicação. O importante seria que ele soubesse explicar com clareza o essencial das matérias selecionadas, tendo em atenção a capacidade e aproveitamento dos alunos, de acordo com a idade que tivessem e o nível que frequentassem.

Numa segunda fase, o protagonista era o discípulo que devia fazer a sua explicação. E, por último, numa terceira fase, supunha o encontro do professor e do aluno, "numa relação triangular, através da multiplicidade de meios ativos com os quais o aluno aprofundava, assimilava, e criava algo seu. Permitindo além da análise, o trabalho criativo". (LOPES, 2002, p. 187).

Para dar a preleção, diz a Ratio nas «Regras Comuns aos Professores das Classes Inferiores»: "o professor recitará em voz alta todo o texto [...]. Depois explicará, de modo muito breve, o seu argumento [...] ler os períodos um a um [...] relacionando-os uns com os outros". (BERTRAN-QUERA, 1986, p. 84).

A repetição tem também um papel fundamental na Ratio. Aqui se prescreve que, no segundo semestre, se repita o material do primeiro; que se façam repetições depois das lições, quotidianamente em casa; e uma repetição geral no começo do ano. (MIRANDA, 2009).

O docente, durante a preleção, deveria ainda ensinar o aluno como estudar cada matéria, de modo a que este saísse da explicação ou "preleção" bem orientado acerca do seu trabalho escolar e, por conseguinte, capaz de um melhor o aproveitamento. A forma de se proceder na "preleção" está amplamente contemplada e explicitada aos professores na Ratio para as lições de Retórica, de Humanidades e de Gramática.

Feita a preleção, a atividade do aluno completa-se com exercícios de composição, oral e escrita, para desenvolver a sua memória, através de disputas, de exercícios de memória, de declamações e de frequentes repetições. (MIRANDA, 2009).

Convém anotar ainda que a Ratio dá uma importância fundamental à memória, como um meio privilegiado no processo de aprendizagem. Todos os dias os alunos cumulativamente devem recitar de cor a preleção do dia anterior e passagens do autor estudado. Ocasionalmente pode ser-lhes exigido que recitem de cor um livro, ou até as lições da semana anterior.

Nas aulas a Ratio requeria também aos alunos diligência, assiduidade, e cuidadosa preparação prévia das aulas e sua posterior memorização, a solicitação ao professor para 
que explicasse o que não fora compreendido, a anotação de tudo quanto se revelar oportuno para ajudar à ulterior memorização da matéria lecionada. Entrando ainda no domínio das regras para o estudo a realizar nos tempos extra curriculares, de igual modo se mandava que o estudante comparece-se a esses tempos de estudo em grupo, que eram as disputas e repetições privadas posteriores às aulas.

\section{Incentivos}

\section{A emulação}

Entre os meios mais eficazes para favorecer o progresso nos estudos e suscitar a "emulação" nos alunos assinalavam-se, além das disputas, os prémios e os cargos honoríficos.

A pedagogia Jesuíta caracterizou-se por uma atividade estimulada no sentido de uma emulação sã, da luta pela conquista de posições de destaque dentro da sala de aula, pela disputa oral combativa, arguta e incansável e por recompensas aos alunos mais dotados.

Gomes (1994, p. 149), sublinha que a "emulação é um dos motores da pedagogia Jesuíta: Honesta aemulatio chama-Ihe a Ratio, Sancta aemulatio haviam-Ihe chamado as Constituições". Deriva, pois, de um verbo latino aemulare, que significa rivalizar e igualar; em pedagogia, foi utilizada para significar competição entre dois grupos.

O facto de a "emulação" ser uma componente fundamental desta pedagogia, levou a que os alunos dos seus Colégios estivessem constantemente ativos e, deste modo, participassem empenhadamente no processo ensino/aprendizagem. Desde o início, no sentido de motivar e estimular os alunos que os Jesuítas praticaram a emulação.

Inácio de Loyola referia assim nas suas Constituições "para maior estímulo dos escolásticos, será bom juntar alguns dos talentos iguais que mutuamente se animem com Sancta emulação" (ABRANCHES, 1975, p. 143). Refere Rodrigues (1917, p. 68), que "a emulação estimula os espíritos e os aplicava, com rigor ao trabalho". O desafio podia organizar-se ou em perguntas do professor e correção dos émulos, ou perguntas dos émulos entre si. Poderiam bater-se um contra um, ou um grupo contra outro grupo (GOMES, 1994). Mas para obviar "esta ambição", procura a Ratio que se estabeleça, no ânimo dos alunos, "o amor sincero da virtude, e educá-los na sólida piedade". (RODRIGUES, 1917, p. 69).

Diz-nos ainda Carvalho (2011, p. 354), que

os estudantes se dividiam nas aulas em dois partidos e "tomavam-se para si, nomes de celebridades oratórias, romanas e gregas, que os estimulavam para a luta [...] consistia em se interrogarem sobre a matéria em estudo e daí alcançarem os lugares notórios da avaliação da classe.

Dentro da lógica da emulação, estão também as sabatinas: no Sábado, recorda-se tudo o que foi ensinado na semana, ou nos dias anteriores. Refere a Ratio segundo França (1952, p. 185), que 
de quando em quando, se oferecem alguns para responder sobre todas as lições ou sobre um livro inteiro. Recolha o professor os melhores e os demais os ataquem cada qual com duas ou três perguntas [...] e não fique isto sem recompensa.

Menciona também Rodrigues (1931, v. II, p. 443), que nas escolas da Companhia se verificava e desenvolvia,

uma atividade contínua tão sabiamente regulada que punha em movimento e proveitoso exercício todas as faculdades dos alunos e que evitava o fastio e o esmorecimento bem prejudicial ao progresso das Letras. Para esse fim, para além da vida quotidiana das aulas prescreviam-se exercícios extraordinários e frequentes que despertassem [...] e the mantivessem vivo e elevado, o empenho e fervor do estudo.

Assim, todos os Sábados se realizavam declamações, desafios ou disputas particulares, no recinto de cada aula. No primeiro Sábado de cada mês, faziam-se esses exercícios com mais solenidade, reunindo-se todas as classes numa só sala ou no pátio das escolas.

Depois da Páscoa, tornavam-se mais aparatosas essas exibições escolares, preparavam-se com mais tempo e realizavam-se em presença de numerosa assembleia.

No início de cada ano letivo, realizavam-se também declamações e disputas. Todo este movimento escolar, refere o mesmo autor, "começou a vigorar entre nós nos Colégios da Companhia desde os primeiros anos que os seus religiosos abriram escolas públicas" (RODRIGUES, 1931, v. II, p. 454). Desta forma se despertava, de modo particular, o sentimento pelos prémios, com que se galardoavam os esforços e êxitos mais brilhantes. Eram, pois, muito estimadas as atividades escolares, nos Colégios da Companhia, sujeitas a prémios, principalmente para os alunos do curso de Letras. Além das disputas solenes, que podiam ser premiadas, a habilitação para os prémios consistia na redação de composições em latim ou em grego, num determinado tempo que fosse fixado. Estes trabalhos nunca eram assinados pelos alunos, mas apenas referenciados com um sinal particular, que se repetia num sobrescrito onde se guardava o nome do aluno, para futura identificação.

Um júri constituído por três pessoas classificava os trabalhos e premiava os autores dos melhores, em festa anual escolar. Havia ainda, os que se iam atribuindo ao longo do ano, na própria aula, quando nela o aluno se distinguia (CARVALHO, 2011). Consistiam esses prémios num lugar de honra entre os condiscípulos, num louvor maior dado pelo professor, ou num livro de capa dourada. (RODRIGUES, 1931).

Uma outra atividade pedagógica muito estimada pelos inacianos era o Teatro escolar. Os Jesuítas privilegiaram nos seus Colégios, a atividade teatral e as disputas literárias como recursos essenciais na orientação pedagógica dos seus alunos. Ao organizarem os concursos literários e levarem à cena peças de teatro, geralmente abertas ao público, não os movia qualquer sentimento de ostentação, mas tão só o desejo de proporcionar aos alunos um bom exercício de disciplina mental e intelectual.

Uma das intenções do teatro escolar era treinar os estudantes no uso da língua latina. Utilizavam a cena como o prolongamento da sua aula, onde os alunos do curso de Letras eram quase sempre os atores, inspirados nos dramas ou em comédias, extraídas de autores clássicos, da Bíblia e até mesmo da experiência da vida quotidiana (ROSA, 2005). Este foi utilizado pelos Padres Jesuítas, como um dos elementos mais ativos do seu 
programa educativo. Para além de constituir momentos de confraternização, às realizações teatrais esta subjacente, a presença de pressupostos pedagógicos decisivos, para o alcance de uma educação sólida e integral.

A primeira peça, representada em Portugal pelos alunos jesuítas, intitulou-se Acolastus, e subiu à cena no Colégio de Santo Antão em Lisboa, em 31 de maio de 1556, conforme nos transmitiu Mezzacapo (1996, p. 78):

In Portogallo, il primo dramma con cuí i professori della Compagnia esordirono, ebbe un esito incoraggiante e sor prendente. Si intitolava Acolastus dal grego, «licenzioso», «pródigo» e venne rappresentato a Lisbona nel patio del collegio di S. Antão il 31 Maggio del 1556.

Refere Rodrigues (1917, p. 70), que o Colégio de Santo Antão iniciou, em 1556, uma série de exibições dramáticas e que "saiu tão brilhante a estreia, e despertou tão vivo entusiasmo particularmente nos estudantes que se viu bem claramente a utilidade e força pedagógica desses exercícios literários". Diz-nos o mesmo autor que continuou, nos anos seguintes, a atividade cénica, passando aos outros Colégios da Província: "em todos se realizaram e repetiram sem interrupção estas solenidades escolares". (RODRIGUES, 1917, p. 70).

Assim, no ano de 1559, no Colégio das Artes, em Coimbra, foi levada à cena por Miguel Venegas, "professor da primeira classe", a tragédia que intitulou Saul Gelboeus. Posteriormente, em 1562, foi exibida a tragédia Cui nomen inditum Achabus. Embora nunca tenha chegado a imprimir os seus versos, Miguel Venegas ganhou fama internacional e, hoje, os seus manuscritos encontram-se dispersos em bibliotecas de vários pontos do Mundo, nomeadamente em cidades como Coimbra, Évora, Lisboa, Roma, Perúsia, Messina, Bolonha, Rio de Janeiro, entre outras. (ROSA, 2005).

Com a tragédia de Acab, que havia sido composta e representada em Coimbra no ano de 1562, Miguel Venegas inaugurou, o género "trágico sacro", dando assim início a um ciclo. (MIRANDA, 2001).

No ano de 1563, no Colégio de Évora, realizar-se-ia uma comédia moral intitulada João de Esfera em Deus, representada na festa de premiação solene. Em outubro do mesmo ano, na inauguração anual dos estudos, no Colégio de Santo Antão, realizar-se-ia uma tragédia do Martírio do Glorioso Mártir São Vicente. Outras peças se seguiriam: em 1569, uma tragédia em Évora sobre a parábola Evangélica de Lázaro e o Rico Avarento; em 1573, Dionísio Tirano da Sicília, a que assistiu o Rei com toda a Corte; em 1576, Nabucodonosor; em 1585, a tragédia A Degolação de São João Baptista; em 1591, no Colégio de Santo Antão o drama do Martírio e Visões de São João Evangelista; e em 1616, no Colégio em Coimbra a tragédia O Rei Baltazar, entre muitas outras. (ROSA, 2005).

Salienta ainda Rodrigues (1917), que teriam sido mais de setenta e cinco as peças escritas pelos Jesuítas para aproveitamento pedagógico dos seus alunos. Destaca-se o nome de alguns dos seus autores, como o Padre Luís da Cruz, cuja obra dramática ganhou fama, para além do comum, sendo, por isso, aplaudido em representações que ficaram célebres. O Padre António de Abreu e o Padre João da Rocha constam também do rol dos mais prestigiados.

A par dos prémios, e dos louvores, como meios de incentivo ao estudo, também os Jesuítas admitiam os castigos nos seus Colégios, conforme nos informam as suas 
Constituições: Inácio de Loyola "determinou que não faltasse a devida correção e castigo aos indisciplinados cuja emenda se não consegue com boas palavras e exortações; e, se o castigo não fosse eficaz, e o punido causasse escândalo, podia chegar-se ao extremo da expulsão". (RODRIGUES, 1931, v. II, p. 446).

Assim, segundo o pensamento do fundador, para a correção dos estudantes, se havia de empregar, gradualmente, boas palavras, admoestações, pena corporal e expulsão, mas em qualquer caso, "se devia proceder com um espirito de brandura e guardar com todos a paz e caridade". (RODRIGUES, 1931, v. II, p. 455).

Os Jesuítas não eram, contudo, amigos dos castigos corporais, como atesta França (1952, p. 60): "não os suprimiram de todo, mas afastaram-se decididamente entre os que mais contribuíram para suavizar a disciplina". Acrescentariam ainda as Constituições segundo Rosa (2005, p. 434-435):

\begin{abstract}
o professor não havia de ser precipitado no castigo, nunca lhe seria permitido castigar por sua mão nem por meio de nenhum da Companhia, era lei que houvesse sempre pessoa estranha, incumbida da correção, por isso chamada corretor e onde não fosse possível se desse o castigo por outro modo conveniente, nunca porém o professor tocasse no aluno.
\end{abstract}

Além disso para efeitos disciplinares, encontravam-se as turmas divididas em grupos chamados "decúrias" de nove ou dez alunos, sob a vigilância de um colega da mesma turma, chamado "decurião" a quem competia observar o comportamento do grupo e informar sobre o comportamento do mesmo.

\title{
Princípios básicos
}

Podemos dizer ainda, sintetizando, que as raízes da Ratio Studiorum se encontravam na própria natureza humana: no homem, na sua transcendência e destino pessoal.

Através de um estudo elaborado por Fernando de Lasala (apud LOPES, 2002, p. 113) tentámos delinear os seus princípios básicos lembrando a sua atualidade:

- A pedagogia da Ratio pretende que o aluno, a partir da sua liberdade, desenvolva ao máximo, de modo harmonioso e segundo uma hierarquia de valores, as suas faculdades mentais, volitivas e afetivas;

- Ao estudante, protagonista da sua aprendizagem, é expressamente exigido um carácter ativo, evitando a passividade, o desinteresse e indiferença;

- O ato educativo é considerado um ato de interações entre o professor e o aluno, isto é, um ato intercomunicativo de ensinamento e aprendizagem mútua entre educador e educando;

- Coloca-se maior ênfase, na formação interior, de acordo com as Constituições (ABRANCHES, 1975, art. 요 813, p. 267);

- Equilibra-se a educação intelectual com a educação do carácter e a educação moral;

- Ensina-se o aluno a sentir, a compreender e a pensar por si próprio; a refletir, a julgar, a crer, a saber ler, a saber estudar e a tomar notas; a saber exprimir-se já 
que a "palavra é o veículo mais universal do pensamento";

- Utiliza-se uma pedagogia diferencial adaptada à idade, possibilidades e atitudes do aluno de uma forma gradual.

Quanto aos elementos pedagógicos da Ratio o autor acrescenta ainda:

1. Um plano de estudos unificado, perfeitamente ordenado e graduado nos programas de cada curso;

2. A forma habitual usada nas aulas é o diálogo "preleção" (interrogação e resposta), a promoção e o estímulo do esforço pessoal, assim como, a partilha do êxito alcançado;

3. Utiliza-se um método basicamente grupal;

4. Utilizam-se os processos do "tríptico" didático jesuítico, isto é, a interação, preleção-repetição-aplicação em exercícios práticos, evitando a passividade.

A Ratio Studiorum fomenta, assim, uma pedagogia do interesse, personalizada, dinâmica e participativa. O trabalho pessoal do aluno e as relações interpessoais convertem-se num eixo de eficácia. (MIRANDA, 2009).

\section{Atualidade da Ratio Studiorum}

O nosso mundo não é nem poderia ser o do século XVI. No entanto, a Ratio tem um incontornável valor histórico-pedagógico. Basta analisarmos alguns textos contemporâneos, como as Características da Educação da Companhia de Jesus, e a Pedagogia Inaciana - Uma Abordagem Prática, para entendermos que a ela foi beber.

A Ratio Studiorum terá sempre atualidade, porque soube fazer uma escolha pertinente a nível antropológico. O homem da Ratio é o homem à imagem e "Deus" pretendia-se a formação do homem completo.

Tudo isto se fundava em valores teológicos, mas também em convicções, em compromissos e na cooperação. A educação vista neste contexto, pode tornar-se um meio para realizar a síntese entre o homem e o mundo, uma forma de reforçar a consciência nas oportunidades da construção humana. Partindo deste princípio,

\footnotetext{
"se o homem é grande", então a sua formação também deve ser exigente, e comprometedora, seja do ponto de vista individual ou social, seja do ponto de vista espiritual. Por essa razão, "muitas orientações educativas" respeitam todas as dimensões que caracterizam a essência do ser humano, ontem e hoje, tal como a motivação, a criatividade, a sociabilidade, a capacidade crítica e a espiritualidade. (LOPES, 2002 apud MIRANDA, 2009, p. 50).
}

Estas como pertencem à essência profunda do ser humano, apresentam-se em todos os tempos ainda que com denominações e modalidades diversas. Na Ratio, encontrase presente esta capacidade de individualizar as dimensões pessoais da figura humana, mas também as características do discernimento, realizada em larga escala. Faz parte deste antigo documento pedagógico, os fins, os objetivos, assim como, os percursos e os melhores instrumentos para se alcançar o fim proposto. Desta forma, podemos sublinhar 
que se trata de um documento educativo-pedagógico da máxima atualidade.

\section{Considerações finais}

A Ratio é fruto do seu tempo. Os Exercícios Espirituais são a "proto pedagogia" da Companhia. Neles está contida a intuição inaciana. Por isso mesmo, neles se fundamenta a tradição da Companhia, e o específico de ser jesuíta.

Existe nos Exercícios Espirituais, uma fidelidade a valores, motivações, objetivos e ideais, que como vimos passou à Ratio Studiorum como metodologia, continuou nas Características da Educação da Companhia de Jesus, e se atualizou no Paradigma Inaciano. As Características da Educação, publicada em 1986, não podendo ser considerada uma nova Ratio é de grande importância, sobretudo, no que diz respeito à concepção pedagógica caracterizada a partir da sua "ideia de homem" e do que significa hoje a herança da visão educativa de Inácio de Loiola nos seus centros Educativos. Existem alguns pressupostos que se mantiveram inalteráveis no tempo.

A comunidade educativa, tal como é entendida hoje é composta por um corpo, que é formado pela comunidade Jesuíta, pelos colaboradores leigos, pelos alunos e suas famílias, e pelos antigos alunos, já que em relação a estes, a educação não esgota com o recebido no tempo da escolaridade.

A educação Jesuíta tem procurado manter o seu carácter peculiar, que transparece na pedagogia praticada, nos planos de estudo e na orientação escolar.

O carisma inaciano pode ser encontrado na inspiração de valores, nas atitudes e no estilo próprio, que caracterizaram tradicionalmente a educação Jesuíta e que devem estar presentes em qualquer Instituição da Companhia. Os princípios educativos dos Jesuítas procuram concretizar a espiritualidade inaciana no complexo mundo da educação à luz das necessidades modernas.

Uma das características que se tem mantido ao longo da história da Companhia é o constante esforço de manutenção do "carácter integrador" da pedagogia Jesuíta. A Companhia tentou sempre responder às exigências das diferentes épocas. A preocupação constante ao longo dos séculos foi a integração entre a fé e a cultura da época. O espírito integrador nasce da visão que o próprio Inácio de Loyola tinha em relação ao mundo e ao homem, referido nos seus Exercícios Espirituais (MONTEIRO, 1991, p. 108). Há, assim, uma profunda consequência para a educação Jesuítica, que não faz compartimentos estanques dos valores humanos e dos valores espirituais, mas antes os integra numa formação harmoniosa. Desta forma, a própria ação pedagógica realizada nas suas Escolas, tal como a procura de um ensino, exigente e de qualidade, baseado na personalização do aluno, significa ação apostólica. A pedagogia dos "magis", tão inaciana e Jesuíta, não consiste em procurar líderes, mas em procurar "o melhor de cada pessoa", o seu desenvolvimento total, integrando todos os aspetos da sua personalidade.

O documento que citámos anteriormente sobre as Características da Educação apresenta ainda três diretrizes procedentes das Constituições e da Ratio Studiorum que nos parecem ser de realçar:

1. O plano de estudos deve ser estruturado cuidadosamente: na ordem seguida, no trabalho diário e no modo como os diversos cursos se relacionam, tendo em 
conta o projeto global da escola;

2. A pedagogia deve incluir a análise, repetição, a reflexão e a síntese, devendo promover a combinação entre a teoria e a prática;

3. A qualidade da formação e a sua profundidade é mais importante para a educação do que a quantidade.

Desta forma, importa sublinhar ainda que a Ratio Studiorum pode ser de muita inspiração para o trabalho educativo nos tempos atuais, porque se centra no encontro pessoal entre o educador e o educando, num processo contínuo de interação e comunicação. Possuindo um conjunto de normas e preceitos, que visam a excelência educativa.

Porque ao individualismo, responde com colaboração, com ajuda recíproca, e com sentido de comunidade no aprender. É ainda proveitosa, no sentido do "ideal personalizador", que leva o educador a considerar o aluno como o merecedor do maior respeito e ajuda para o desenvolvimento de todas as suas potencialidades. Pretende que o aluno seja capaz de aprender por si próprio, durante toda a vida, que seja ativo, interessado, participativo no processo educativo, e não mero recipiente de informações.

A Ratio ensina e valoriza a generosidade, o trabalho em equipa, a solidariedade, porque apela a uma educação onde o aluno é convidado a desenvolver, de uma forma harmoniosa e equilibrada todas as faculdades intelectuais, afetivas e volitivas. Ilumina também o trabalho do professor, tendo em vista o estímulo da excelência ao qual o aluno deve chegar.

\section{Referências}

ABRANCHES (S. J.), Joaquim Mendes. As Constituições da Companhia de Jesus. Lisboa: Província Portuguesa da Companhia de Jesus, 1975.

BERTRÁN-QUERA, Miguel; LABRADOR, C.; ESCALERA, J. M. La Ratio Studiorum de los Jesuitas. Madrid: Publicaciones de la Universidad Pontificia de Comillas, 1986.

CARVALHO, Rómulo. História do Ensino em Portugal. Desde a Fundação da Nacionalidade até ao fim do Regime de Salazar-Caetano. Lisboa: Fundação Calouste Gulbenkian, 2011.

CODINA MIR (S. J.), Gabriel. Aux Sources de la Pédagogie des Jésuites. Le Modus Parisiensis. Roma: Bibliotheca Instituti Historici Societatis lesu, 1968.

DUMINUCO, Vicent J. (Ed.). The Jesuit Ratio Studiorum. 400 th Anniversary Perspectives. New York: Fordham University Press, 2000.

FRANÇA, Leonel. O Método Pedagógico dos Jesuítas. Rio de Janeiro: Livraria Agir Editora, 1952.

GIL, Eusébio (Ed.). La Pedagogia de los Jesuítas, ayer y hoy. Madrid: Publicaciones de la Universidad Pontificia de Comillas, 1999.

GOMES, Joaquim Ferreira. O Modus Parisiensis como Matriz da Pedagogia dos Jesuítas. Revista Portuguesa de Filosofia, Lisboa, n. 50, p. 179-196, 1994.

O Ratio Studiorum da Companhia de Jesus. Revista Portuguesa de Pedagogia, Lisboa, Ano XXV, n. 2, p. 131-154, 1991. 
GOMES (S. J.), Manuel Pereira. Ratio Studiorum dos Jesuítas: carisma, inovação, atualidade. Revista Portuguesa de Filosofia, Lisboa, n. 55, p. 219-227, 1999.

GRACOS. Características da Educação da Companhia de Jesus. Grupo de Reflexão e Análise dos Colégios da Companhia de Jesus. Lisboa, 1986.

LASALA CLAVER, Fernando Jesús de. La Ratio Studiorum de la Compañía de Jesús. Historia y esencia de un modelo pedagógico. Revista Miscelânea Comillas, Madrid, n. 84, p. 169-171, 1986.

LOPES, José Manuel Martins. O Projeto Educativo da Companhia de Jesus: dos Exercícios Espirituais aos nossos dias. Braga: Universidade Católica Portuguesa, 2002.

MEZZACAPO, Maria Cristina. II Ruolo Sócio-Politico e Culturale dei Gesuíti nel Portogallo Pré-Pombalino. Perugia: Facoltá di Lettere e Filosofia, corso di Láurea in Língua e Letterature Straniere Moderne, 1996.

MIRANDA, Margarida. Código Pedagógico dos Jesuítas: Ratio Studiorum da Companhia de Jesus. Lisboa: Esfera do Caos, 2009.

. Teatro Sacro Jesuítico: Um esclarecimento a propósito da exposição do Colégio Romano à Universidade Gregoriana. Revista Brotéria, Lisboa, n. 153, p. 618-625, 2001.

MONTEIRO, Miguel Maria Santos Corrêa. Os Jesuítas e o Ensino médio - Contributo para uma Análise da Respetiva Acão Pedagógica. Lisboa: Faculdade de Letras da Universidade de Lisboa, 1991.

RODRIGUES (S. J.), Francisco. A Formação Intelectual do Jesuíta: Leis e Factos. Porto: Livraria Magalhães \& Moniz Editora, 1917.

. História da Companhia de Jesus na Assistência de Portugal, v. 4. Porto: Livraria Apostolado da Imprensa, 1931, 1938, 1944 e 1950.

ROSA, Teresa Maria Rodrigues da Fonseca. História da Universidade Teológica de Évora. Lisboa: Instituto da Educação, Universidade de Lisboa, 2013 [ebook].

. Monumenta Histórica: O Ensino e a Companhia de Jesus séculos XVI a XVIII (1540-1580). Lisboa: Instituto da Educação, Universidade de Lisboa, 2015 [ebook].

O Colégio da Ascensão de Angra do Heroísmo: Uma Análise Pedagógica da Companhia de Jesus - um Contributo para a História da Educação em Portugal. Ponta Delgada: Universidade dos Açores, 2005.

TERESA MARIA RODRIGUES DA FONSECA ROSA é Doutora em Ciências da Educação, especialidade em História da Educação pela Universidade dos Açores. Bolseira/investigadora da FCT (Fundação para a Ciência e Tecnologia do Ministério da Educação). Pós-doutoranda em História da Educação, no Instituto de Educação da Universidade de Lisboa e Investigadora doutorada da Uidef (Unidade de Investigação e Desenvolvimento para a Educação e Formação), do Instituto de Educação da Universidade de Lisboa. Investigadora/Colaboradora do Gceap - Grupo de Pesquisa Cultura e Educação na América Portuguesa.

Endereço: Instituto de Educação da Universidade de Lisboa - Alameda da Universidade 1649-013 - Lisboa - Portugal.

E-mail: teresadafons@gmail.com 